\title{
A memória da greve da FNM/FIAT na Imprensa Operária da Baixada Fluminense
}

\author{
Alvaro de Oliveira Senra* \\ Flávio Anicio Andrade ${ }^{* *}$
}

\begin{abstract}
Dedicamos este artigo a João Pedro de Souza Neto, militante do movimento popular da Baixada Fluminense.

A classe é definida pelos homens enquanto vivem sua própria história, e, ao final, esta é sua única definição.
\end{abstract}

Edward P. Thompson

Resumo: Este texto aborda o registro da greve promovida pelos operários da FIAT Diesel, em Duque de Caxias-RJ, no ano de 1979. Por suas reivindicações e formas de organização e luta, essa greve pode ser considerada como um momento do "novo sindicalismo" brasileiro. Ao mesmo tempo, utiliza-se como fonte privilegiada de tal análise não o registro produzido pela grande imprensa, mas um jornal que se propôs divulgador do movimento popular da Baixada Fluminense: o Jornal da Baixada, editado em São João de Meriti-RJ.

Palavras-chave: Imprensa operária - Sindicalismo - Movimentos sociais

\begin{abstract}
This paper evaluates the record of the strike organized by the workers of FIAT Diesel, in Duque de Caxias, Rio de Janeiro state, in 1979. Due to its demands and forms of organization and struggle, this strike can be considered as a moment of "new unionism" in Brazil. At the same time, is used as a prime source of such an analysis not the records produced by the mainstream media, but by a newspaper that proposed itself to disclose the popular movement of the Baixada Fluminense: Jornal da Baixada, published in São João de Meriti-RJ.
\end{abstract}

Keywords: Workers press - Unionism - Social movements

* Doutor em Ciências Sociais pela UERJ, professor do CEFET-RJ.

** Doutor em Educação pela USP, professor do Instituto Multidisciplinar da UFRRJ. 


\section{Considerações iniciais}

A consciência democrática e os direitos sociais do Brasil atual, mesmo que ainda comportem muitas limitações em relação às possibilidades e às necessidades da cidadania contemporânea, em muito devem à mobilização e à luta dos trabalhadores no período de crise do Regime Militar (1964-1985). A partir de meados da década de 1970, coincidindo com a crise de legitimidade dos governos militares, o fortalecimento da oposição parlamentar legal reunida no Movimento Democrático Brasileiro (MDB, depois PMDB) foi correlata à expansão de movimentos sociais no campo (principalmente nos locais de expansão das fronteiras agrárias) e de inúmeras lutas desencadeadas nas áreas urbanas, sobretudo nas periferias metropolitanas em franco crescimento.

Esses movimentos e lutas envolveram a participação de sujeitos políticos tradicionais de oposição, oriundos em grande parte de partidos e grupos que militavam antes da implantação do Regime Militar, em 1964, assim como de indivíduos que atuavam à margem de organizações políticas, correntes oriundas de dissidências dos partidos de esquerda tradicionais e de segmentos que redirecionaram suas opções políticas, como ocorreu com frações do cristianismo "progressista", de grande importância para a sustentação da oposição societária aos militares, nas décadas de 1970 e 1980.

Além dos movimentos de organização de moradores por melhores condições de vida nas grandes cidades e em suas periferias, de luta contra a carestia, ou contra o racismo, a vida sindical conheceu um florescimento a partir da segunda metade da década de 1970, atingindo não somente as categorias operárias, mas também aquelas formadas por funcionários públicos, como a dos professores ou dos médicos. Além da ampliação dos movimentos sociais, ocorreram em várias situações condições políticas que possibilitaram a articulação entre essas várias frentes de luta. A existência de uma imprensa de oposição "alternativa", resultado do afrouxamento da censura e da atividade de grupos que deram a esses jornais o papel de uma "face pública" para a difusão de um ideário oposicionista, geralmente vinculado a correntes de esquerda atuando ainda em condições de ilegalidade.

O papel desempenhado pelos movimentos relacionados às classes e aos segmentos sociais subalternos, que foram retomados ou reinventados ainda sob as duras condições impostas pelos governos militares, teve importância capital no processo de fortalecimento e amadurecimento da sociedade civil brasileira, permitindo avanços substanciais na construção de uma concepção de democracia não limitada às necessárias liberdades formais, mas capaz de incorporar ao conceito de cidadania e aos processos decisórios muitas das preocupações e reivindicações que esses movimentos explicitaram.

As consequências políticas e sociais das lutas travadas sob o Regime Militar podem ser comprovadas nos avanços registrados no texto da Constituição de 1988, escrito poucos anos após o retorno à democracia. A Constituição legitimou direitos inéditos e reconheceu a existência de uma dívida social originária das condições excludentes em que se deu o desenvolvimento do capitalismo no Brasil, principalmente ante o Regime Militar.

Os movimentos sindicais e o conjunto da mobilização social que citamos relacionam-se, inicialmente, à resistência contra a deterioração salarial e das condições de vida ocorridas durante os governos militares. 
Um dos traços mais marcantes do Regime Militar foi a adoção de políticas econômicas de natureza concentracionista, que, combinadas com a repressão ao movimento operário, resultaram em uma forte diminuição do valor real dos salários. Essas políticas foram correlatas à manutenção de elementos oriundos do desenvolvimentismo que vinha sendo implementado ao longo dos governos varguistas e do período democrático (1945-1964). A legitimação do regime foi possível enquanto a disponibilidade de capitais externos e o crescimento econômico permitiram satisfazer demandas de parcelas da população. No entanto, a partir de meados da década de 1970, a diminuição das taxas de crescimento econômico e o aumento inflacionário expuseram as consequências do aumento da desigualdade social.

A economia brasileira, que vinha, posteriormente à década de 1930, conhecendo elevadas taxas médias de crescimento econômico anual, notadamente do setor industrial, com picos na segunda metade da década de 1950 (em 1958, por exemplo, o PIB cresceu $10,8 \%$ e o produto industrial, $16,8 \%$ ) e nos primeiros anos da década de 1970 (em 1973, 14\% de crescimento do PIB e 16,6\% de crescimento industrial), entrou em processo de gradual desaceleração em meados da década de 1970. O impacto da crise do petróleo, produto do qual o Brasil era grande importador, além da redução da liquidez financeira internacional diminuíram em muito a capacidade de iniciativa econômica do Estado brasileiro. Esse decréscimo, por sua vez, foi acompanhado pela aceleração dos índices inflacionários, que já em 1975 atingiram $32,7 \%$, chegando, em 1979, a $77,2 \%{ }^{1}$

Outro aspecto da política econômica dos militares, de favorecimento à concentração de capitais, foi complementado pela contenção dos salários da classe trabalhadora, tarefa facilitada pela repressão ao movimento sindical e sua consequente desarticulação. O valor real do salário mínimo, tendo como base índices próximos a 100 no ano de 1960 e 92,49 em 1964, caiu para 76,03 em 1966, 70,39 em 1968 e 68,93 em 1970, num processo de declínio que apresentou continuidade: em 1978 , esse valor tinha alcançado apenas $48,53 .^{2}$

A voz de dirigentes vinculados aos setores renovadores do sindicalismo, atuantes na segunda metade da década de 1970, confirma a importância de combinar a luta por objetivos econômicos à necessidade de superar os instrumentos políticos que sufocavam a liberdade sindical, o que era visto como passo necessário para a existência de condições de resistência ao arrocho salarial e de defesa dos interesses dos trabalhadores. Esses instrumentos compreendiam, então, não somente os aparatos legais da repressão utilizados pelo Regime Militar, como o Ato Institucional $n^{\circ} 5$ (Al-5), mas formas de adaptação de cúpulas dirigentes às exigências de submissão dos sindicatos ao Estado, compreendidas na Consolidação das Leis do Trabalho (CLT), instituída no período varguista e mantida tanto no período democrático como após 1964.

Em depoimento prestado ao III Ciclo de Debates promovido pelo Teatro Casa Grande, no Rio de Janeiro, 1978, João Paulo Pires Vasconcelos, então presidente do Sindicato dos Metalúrgicos de João Monlevade, no Vale do Aço Mineiro, resumiu da seguinte forma a grande questão política a ser enfrentada:

O movimento sindical brasileiro está contido numa camisa-de-força, que é a CLT. A CLT foi uma transcrição, uma tradução ipsis litteris do modelo corporativo fascista de Mussolini, que solidificou com a outorga

ALVES, Maria H. Estado e oposição no Brasil (1964-1984). 4. ed., Petrópolis: Vozes, 1984, p. 331.

2 MANTEGA, Guido; MORAES, Maria. Acumulação capitalista e crises no Brasil. Rio de Janeiro: Paz e Terra, 1979 , p. 75. 
do ditador Getúlio Vargas, e que em vez de ser um instrumento de libertação do trabalho é porrete na mão do capital. De lá pra cá, se acentuou o caráter fascista-corporativista nas atuais relações entre capital e trabalho. Existem ainda as imposições das leis de exceção. Fala-se muito em extinção do $\mathrm{Al}-5$, mas de que adianta extinguir o Al-5 se persistir a CLT? Para o trabalhador, pouco significado vai ter porque o Ministério do Trabalho, o órgão que exerce a coerção sobre os sindicatos, é mantido pelo próprio trabalhador, através de $20 \%$ de desconto de sua contribuição sindical. O que pretende o movimento sindical diante da CLT? A sua total extinção, isto é, a extinção da tutela. ${ }^{3}$

Presente no mesmo Ciclo de Debates, Luís Inácio da Silva, o Lula, então presidente do Sindicato dos Metalúrgicos de São Bernardo do Campo e Diadema, expôs a necessidade de eliminação de um instrumento de cooptação previsto pela legislação trabalhista, que era a existência de juízes classistas:

\begin{abstract}
Nossa estrutura sindical permite que um trabalhador seja um ministro classista, ou um vogal da Justiça do Trabalho, ganhando 35, 40 ou $50 \mathrm{mi}$ Ihões de cruzeiros. E comecei a perceber, de 69 a 72 - e aí não precisa ser inteligente não, precisa é ser honesto - como seria fácil eu me tornar um grande dirigente sindical, um pelego-mor, se eu, que ganhava seis mil cruzeiros por mês, me tornasse um juiz classista e passasse a ganhar 35 mil cruzeiros por mês. Iria me acomodar com meu novo padrão de vida, poderia comprar um Volkswagen novo para minha esposa, passaria a ter medo de falar mal do governo e de brigar com as empresas, enfim, passaria a ter medo de fazer a única coisa que resta a um dirigente sindical que se preza, que é fazer um verdadeiro sindicalismo. ${ }^{4}$
\end{abstract}

O fortalecimento dos movimentos de renovação sindical e das correntes que questionavam a estrutura legal autoritária que regia as relações de trabalho e impunha severos limites às lutas sindicais se tornou um dos sintomas de um movimento mais geral, relacionado à ampliação da oposição política e social e ao período de declínio do Regime Militar.

Na segunda metade da década de 1970 já podiam ser observados os sinais de que a crise econômica e social estava abalando as bases de legitimação do regime: a votação obtida pela oposição consentida (o Movimento Democrático Brasileiro - MDB) ampliava-se desde as eleições parlamentares de 1974; mesmo com o endurecimento da legislação eleitoral promovido pelo governo de Ernesto Geisel em 1977 (o "Pacote de Abril”), e a posterior reforma partidária que objetivou pulverizar a oposição parlamentar, essa votação continuou crescendo até 1982, quando se realizaram as últimas eleições sob o Regime Militar.

Por sua vez, os movimentos sociais reivindicatórios estavam em processo de franco crescimento, diante da deterioração das condições de vida, sobretudo nas periferias urbanas e nas áreas de expansão do capitalismo agrário.

Embora os sujeitos interessados no fim dos governos militares não se limitassem às classes subalternas (posto que o elemento liberal teve grande importância naquele período, hegemonizando, no final, a transição para a democracia), foram as suas lutas que trouxeram uma série de inovações organizativas e de demandas sociais, marcando sua vida política desde então e dando traços inéditos à democracia brasileira.

3 CHICO JR (et al.) Consolidação das leis do trabalho ou liberdade sindical? In: BOSI, Alfredo (et al.) Conjuntura nacional: III ciclo de debates do Teatro Casa Grande. Petrópolis: Vozes, 1979, p. 244-245.

4 Ibidem, p. 248. 
Diante da urgência das lutas econômicas e da necessidade de libertação das travas representadas pelo autoritarismo da política e da legislação sindical, várias categorias profissionais, em diversas partes do país, buscaram se organizar (ou se reorganizar) e ressignificar tradições anteriores, gerando, no limite, um fenômeno de renovação da identidade sindical e da própria autorreferência social e cultural de amplos setores da classe trabalhadora.

Temos, então, um momento importante do processo de construção histórica da identidade da classe trabalhadora no Brasil, no qual ficaram registrados termos como "novo sindicalismo", "oposições sindicais" ou "sindicalismo combativo", marcos de uma época da história social brasileira. A vida política (e não somente sindical) e sua simbologia no Brasil atual trazem consigo uma grande carga do papel desempenhado pela geração de trabalhadores que vivenciou o período de crise do Regime Militar.

Aquele período presenciou a afirmação de novos marcos relacionais entre trabalhadores, sindicatos, patronato e Estado no Brasil. Embora, obviamente, não se deva subestimar a influência dos componentes políticos que se construíram no processo de organização e identificação dos trabalhadores e de suas lutas em períodos anteriores (a ação, por exemplo, do Partido Comunista Brasileiro e do trabalhismo de origem varguista), a repressão às correntes atuantes antes de $1964 \mathrm{e}$ a influência de novos segmentos contribuíram para que novas questões fossem postas pelos trabalhadores, ou então mais enfatizadas do que em outros momentos históricos: o fim da Consolidação das Leis do Trabalho (CLT), a organização por local de trabalho, a articulação com outras frentes do movimento social, a crítica às cúpulas sindicais.

As práticas sindicais e políticas daqueles homens e mulheres tiveram grande contribuição para o refazer da identidade da classe trabalhadora brasileira. As classes sociais não são entendidas por nós como "coisas", dados estruturais à margem do processo histórico, mas se constroem em um constante fazer, relacionando-se com as outras classes presentes na sociedade, escrevendo e reescrevendo tradições.

Recorremos, aqui, à análise clássica do processo de formação da classe operária inglesa, quando o historiador E. P. Thompson concluiu que

a noção de classe traz consigo a noção de relação histórica. Como qualquer outra relação, é algo fluído que escapa à análise ao tentarmos imobilizá-la num dado momento e dissecar sua estrutura. A mais fina rede sociológica não consegue nos oferecer um exemplar puro de classe, como tampouco um do amor ou da submissão. A relação precisa estar sempre encarnada em pessoas e contextos reais. Além disso, não podemos ter duas classes distintas, cada qual com um ser independente, colocando-as a seguir em relação recíproca. Não podemos ter amor sem amantes, nem submissão sem senhores rurais e camponeses. A classe acontece quando alguns homens, como resultado de experiências comuns (herdadas ou partilhadas), sentem e articulam a identidade de seus interesses entre si, e contra outros homens cujos interesses diferem (e geralmente se opõem aos seus). ${ }^{5}$

Continua o autor: "a consciência de classe é a forma como essas experiências são tratadas em termos culturais: encarnadas em tradições, sistemas de valores, ideias e formas institucionais". 6

5 THOMPSON, E. P. A formação da classe operária inglesa. V. I: a árvore da liberdade. Rio de Janeiro: Paz e Terra, 1987, p. 10.

6 Ibidem. 
Em um país com as dimensões do Brasil, onde o desenvolvimento do capitalismo assumiu especificidades regionais, o mesmo ocorrendo com a composição da classe trabalhadora, sujeita a relações econômicas e a tradições políticas e culturais diferenciadas, os fenômenos de renovação do movimento sindical e de organização das classes subalternas necessariamente apresentariam singularidades.

O registro e a análise dos movimentos de trabalhadores a partir da segunda metade da década de 1970 constituem importante objeto de interesse acadêmi$\mathrm{co}$, concentrando-se, sobretudo, nos movimentos iniciados na região industrial do $A B C$ Paulista, definido como local do desenvolvimento de um novo modelo sindical, caracterizado pela ruptura com antigas práticas. Segundo o historiador Marcelo B. Mattos,

\begin{abstract}
quando em fins dos anos 70 uma onda de greves, detonada a partir do ABC paulista, sacudiu o país, estendendo aos limites as amarras da estrutura sindical oficial e alargando os horizontes políticos do processo de abertura, os analistas do movimento operário brasileiro cunharam a expressão "novo sindicalismo" para qualificar o fenômeno. Como toda novidade, o "novo sindicalismo" opunha-se a uma tradição, um "velho sindicalismo" ou "velhos sindicalismos". As especificidades das novas manifestações sindicais foram definidas em oposição tanto aos sindicatos controlados do período ditatorial, como ao movimento sindical de pré-64, genericamente definido como "sindicalismo populista". Grande parte da literatura especializada, entretanto, construiu esta noção de "novo sindicalismo" a partir de uma generalização do caso típico de S. Bernardo e de uma caracterização sumária dos momentos precedentes do sindicalismo brasileiro.?
\end{abstract}

No entanto, limitar essas experiências ao ocorrido em uma região industrial específica, por mais importância econômica e política que ela tivesse, significaria reduzir os seus significados e desdobramentos a uma tradição operária específica e a um contexto espacial e temporal excessivamente delimitado.

No Rio de Janeiro, assim como em outras partes do país, experiências de renovação sindical e de lutas operárias se deram a partir de contextos próprios, de demandas específicas, sendo também caudatários de tradições políticas e organizativas anteriores diferenciadas das referências utilizadas pelos trabalhadores do ABC Paulista.

Na cidade do Rio de Janeiro e em sua região metropolitana, o final da década de 1970 assistiu ao fortalecimento de oposições sindicais e à constituição de diretorias combativas nos sindicatos de várias categorias importantes. No Sindicato dos Metalúrgicos, já em 1977, uma chapa oposicionista, liderada por um operário da FIAT Diesel, Oswaldo Pimentel, conseguiu vencer as eleições e constituir a nova diretoria. ${ }^{8}$

Nos anos seguintes, a categoria metalúrgica enfrentou várias greves, sendo a mencionada fábrica da FIAT Diesel, em Duque de Caxias, um dos seus polos mais ativos, dispondo seus trabalhadores de instrumentos de mobilização atuantes e eficazes, como a Comissão de Fábrica que organizou greves entre 1978 e 1981, radicalizando suas posições e enfrentando, inclusive, a direção do Sindicato dos Metalúrgicos. ${ }^{9}$

7 MATTOS, Marcelo B. Novos e velhos sindicalismos: Rio de Janeiro (1955-1988). Rio de Janeiro: Vício de Leitura, 1998, p. 11.

8 Ibidem, p. 152.

9 Ibidem, p. 193. 
Aqui se aborda o registro da greve promovida pelos operários da FIAT de Duque de Caxias em 1979. Pelo contexto em que aquele movimento se constituiu, e por suas reivindicações e formas de organização e luta, a greve dos metalúrgicos da FIAT Diesel pode ser considerada como um dos marcos do "novo sindicalismo" brasileiro.

Ao mesmo tempo, utiliza-se como fonte privilegiada de tal análise não o registro produzido pela grande imprensa, mas um jornal que se propôs divulgador do movimento popular da Baixada Fluminense: o Jornal da Baixada, editado em São João de Meriti-RJ.

\section{O Jornal da Baixada: contexto e condições históricas de sua produção}

O Jornal da Baixada é um exemplo a mais no interior de uma constelação de pequenos periódicos que fizeram parte da imprensa alternativa, difundida ao longo da "abertura política" promovida a partir do governo do General Ernesto Geisel (1974-1979), quando o afrouxamento da censura e da repressão permitiu que nascessem órgãos vinculados a correntes de opinião (em muitos casos, clandestinas ou semiclandestinas) ou então a temáticas mais específicas, como jornais sindicais ou dedicados a "questões" nesse momento emergentes, como a luta pelo direito à opção sexual, contra o racismo ou em defesa do meio ambiente.

A existência de uma imprensa alternativa é anterior ao Al-5 e, em alguns casos, antecede ao próprio Regime Militar, como ocorreu com o jornal mineiro Binômio. Outros jornais, cuja criação se deu posteriormente ao golpe de 1964, foram estabelecendo o padrão de imprensa oposicionista que caracterizou os jornais alternativos, embora com motivações, formatos e estruturas bastante diferenciados. ${ }^{10}$

De modo geral, esses jornais se organizavam em torno de estruturas militantes voluntárias, contando, no máximo, com pequenos núcleos profissionais, responsáveis por sua edição e registro. Embora pudessem ser encontrados em bancas ou livrarias, eram mais comumente vendidos por militantes em rodoviárias, praças, universidades ou, então, em manifestações públicas. À parte um jornal da importância do Pasquim, cuja existência é anterior à "abertura" e que reuniu uma brilhante equipe profissional que soube se valer do humor e da cultura para fazer oposição ao regime, chegando a 200.00 exemplares semanais de tiragem, a maioria teve vida efêmera e condição financeira bastante precária.

Alguns dos mais conhecidos jornais alternativos (Em Tempo, Convergência Socialista, Hora do Povo) eram vinculados a grupos organizados ou a frentes de esquerda, tinham caráter nacional e boa estrutura militante e, por isso, conseguiram sobreviver por mais tempo.

No caso do Jornal da Baixada, de curta existência e cuja estrutura fundamentalmente amadora se sustentava na ação de militantes de esquerda vinculados ao movimento popular daquela região periférica do Rio de Janeiro, sua produção e distribuição também se baseavam fundamentalmente sobre o trabalho voluntário de militantes do movimento popular e sindical da região.

10 GENTILLI, Victor. A imprensa brasileira mudou bastante depois do Al-5... mas não como decorrência dele. In: MUNTEAL Fo, Oswaldo; FREIXO, Adriano; VENTAPANE, Jacqueline. Tempo negro, temperatura sufocante: Estado e sociedade no Brasil do Al-5. Rio de Janeiro: Editora PUC-Rio; Contraponto, 2008, p. 304. 
A Baixada Fluminense é formada por vários municípios do entorno da cidade do Rio de Janeiro. Apesar da proximidade e das fortes ligações econômicas com essa cidade, até a fusão ocorrida na década de 1970 a Baixada pertencia politicamente ao Estado do Rio de Janeiro, desvinculada do Distrito Federal ou, posteriormente, da Guanabara.

A partir da década de 1930, com a drenagem das áreas alagadiças, a Baixada passou gradativamente da condição de área de economia rural para a de periferia urbana da cidade do Rio de Janeiro. A construção dos ramais ferroviários e o loteamento de grandes áreas, principalmente nos municípios de Nova Iguaçu e de Duque de Caxias (que posteriormente perderiam parte de seu território para os novos municípios de São João de Meriti e Nilópolis), atraíram milhares de trabaIhadores e imigrantes, que ali se fixaram pela possibilidade de compra de terrenos baratos e pelo transporte relativamente fácil e rápido para os locais de trabalho.

As transformações sociais na região foram extremamente rápidas. Em Nova Iguaçu, principal município da Baixada Fluminense,

\begin{abstract}
de 45.649 habitantes em 1950, a população aumentou para $359.364 \mathrm{em}$ 1960 e para 727.140 em 1970, fazendo de Nova Iguaçu a cidade de mais rápido crescimento entre as maiores do país. Em 1950, 46,60\% da população da municipalidade ainda residia em áreas rurais, mas em 1980 essa cifra baixara para $0,29 \%$. O crescimento tornou-se mais lento durante a década de 70, mas a população aumentara para 1.094.805 em 1980, transformando a cidade na sétima maior do país."
\end{abstract}

Processos assemelhados ocorreram em todas as cidades da Baixada Fluminense, com a evidente constatação de que o aumento populacional não foi acompanhado de uma adequada urbanização e da expansão de serviços urbanos essenciais, como educação e saúde. Por sua vez, a condição periférica não significou ausência de industrialização: grandes empreendimentos estatais, como a Fábrica Nacional de Motores (FNM) e a Refinaria Duque de Caxias (REDUC), além de empresas privadas, como químicas e metalúrgicas de grande porte, empresas alimentícias e de transportes e um sem-número de pequenas empresas, deram à região uma importância econômica considerável.

Em termos políticos, tradicionalmente organizada em torno de lideranças personalistas e de práticas clientelistas, a Baixada Fluminense vivenciou, a partir da segunda metade da década de 1970, o florescimento de movimentos associativos, profissionais e culturais. A ação de ativistas ligados à Igreja Católica, com incentivo da Diocese de Nova Iguaçu, a presença do Partido Comunista Brasileiro $(P C B)$ e de pequenos grupos de esquerda contribuíram para a difusão de movimentos sociais. Ao mesmo tempo, as estruturas locais do Movimento Democrático Brasileiro (MDB), de tradição fisiológica e "chaguista”, mostravam-se pouco abertas à participação popular e a práticas democráticas.

A hegemonia do grupo político vinculado ao governador Chagas Freitas no estado do Rio de Janeiro, no período posterior à fusão, fez com que, apesar da adesão desse grupo ao PMDB oposicionista em nível nacional, não se refletisse em práticas políticas participacionistas ou de maiores investimentos sociais no estado. Político conservador, filiado antes de 1964 ao Partido Social Progressista (agremiação que havia sido criada e era liderada pelo político paulista Adhemar de Barros), Chagas Freitas, por ocasião da reforma partidária promovida pelo Regime

11 MAINWARING, Scott. Igreja católica e política no Brasil (1916-1985). São Paulo: Brasiliense, 1989, p. 209. 
Militar, chegou a ingressar no Partido Popular (PP) organizado por Tancredo Neves, mantendo filiação no PMDB após o fracasso daquela breve iniciativa.

Entre 1978 e 1980, com a difusão das experiências associativas por locais de moradia, esforços de sua organização em nível municipal foram realizados, e Federações de Associações de Moradores foram sendo fundadas nos principais municípios da região. O modelo foi o Movimento de Amigos de Bairros (MAB), em Nova Iguaçu, mas processos semelhantes levaram ao nascimento da Associação de Bairros de Meriti, depois Federação das Associações de Moradores de São João de Meriti (ABM), e ao Movimento de União de Bairros (MUB), em Duque de Caxias. A composição política das direções desses movimentos levou-os a prestar solidariedade e a buscar colaborar com as mobilizações sindicais, como as de metalúrgicos e de professores, além de apoiar os movimentos pela anistia política e pelo retorno à democracia. ${ }^{2}$

O Jornal da Baixada se propôs a dar voz a esses movimentos e, nesse sentido, se constitui em uma fonte relevante para a análise da ação política dos segmentos envolvidos na reorganização da sociedade civil, naquele período histórico.

\section{A narrativa da greve da FIAT Diesel em julho de 1979 pelo Jornal da Baixada}

O objeto privilegiado que este texto aborda teve seu desencadeamento na manhã do dia 23 de julho de 1979, quando os operários do galpão "Brasília" da antiga Fábrica Nacional de Motores (FNM), que então havia se tornado a FIAT Diesel (unidade fabril e divisão comercial responsável pela fabricação de motores e veículos pesados do grupo multinacional italiano), decidiram cruzar os braços imediatamente. O movimento teve rápida expansão entre os operários, e antes do meio-dia toda a fábrica estava parada.

Desde o mês anterior, junho, o sindicato dos metalúrgicos e a direção da empresa se reuniram para negociar uma pauta de reivindicações apresentada pelos trabaIhadores, sem que houvesse nenhum resultado concreto positivo para estes últimos.

A lista composta por 33 pontos apresentada pelo sindicato enumerava, além da reivindicação de aumento salarial, também demandas caracterizadas pelo "espírito da época", colocando em questão o despotismo da direção fabril: a pauta continha a reivindicação de devolução do desconto no salário dos empregados que, em razão de uma greve de ônibus então recentemente ocorrida na Baixada Fluminense, não puderam ir trabalhar, demandando, ainda, a estabilidade dos membros da delegação sindical e da comissão de fábrica.

Outros pontos apresentados avançavam na direção do questionamento das condições de trabalho a que estavam sendo submetidos os funcionários da empresa, incluindo o questionamento ao recurso constante às demissões como estratégia de controle fabril adotada como regra pela direção da fábrica, a intensificação do ritmo de trabalho via aceleração da linha de montagem e a imposição da "polivalência" dos operadores. Nas palavras dos próprios trabalhadores da FIAT, expressas na "Carta à População", elaborada durante a greve que terminou advindo:

A comida na fábrica é péssima. Muitas vezes nos são servidos alimentos podres. Não nos é garantido o mínimo necessário para mantermos nossas energias para enfrentarmos o trabalho estafante. [...]

12 MAINWARING, op. cit., p. 216. 
Trabalhamos sob um barulho constante e de intensidade superior ao permitido por lei e não recebemos taxa de insalubridade.

Trabalhamos aspirando fumaça e gases tóxicos, óleo e querosene e não recebemos insalubridade.

Trabalhamos sob temperaturas superiores a $40^{\circ} \mathrm{C}$ e não recebemos insalubridade. Isto é "privilégio" só de alguns escolhidos pela empresa. [...]

Trabalhamos em funções iguais e recebemos salários diferentes. Isso só interessa aos patrões que assim aumentam os seus lucros através de pagamentos de salários mais baixos, além de incentivar a competição entre os operários. ${ }^{13}$

Por suas motivações, tratava-se, portanto, de um movimento grevista que não se diferenciava essencialmente de outros que no mesmo período estavam ocorrendo na região metropolitana do Rio de Janeiro e em outras regiões com forte presença da indústria na paisagem urbana (o mencionado caso do ABC Paulista sendo o de maior repercussão nacional). Porém, ao passar a ser noticiada pelo Jornal da Baixada, a greve da FIAT adquiriu não somente maior impulso e força, como de certa forma veio a se tornar parte de um movimento de luta política de alcance mais geral e que tinha no citado jornal um importante elemento de divulgação, de articulação e de apoio.

Tratava-se de tentar induzir uma mudança na cultura política da região, marcada fortemente, como já indicado, por práticas autoritárias e clientelistas, as quais não raramente caminhavam de mãos dadas com o recurso à violência pura e simples - característica, aliás, que por muito tempo deu à Baixada Fluminense o estigma de região mais violenta do Brasil: basta lembrar que o município de Duque de Caxias, onde se localizava a unidade industrial da FIAT, havia ficado conhecido nacionalmente desde a década de 1950 por ser o feudo político de Tenório Cavalcanti, o Homem da Capa Preta, que participava de suas atividades sempre carregando uma metralhadora a tiracolo.

Dessa forma, nas páginas do Jornal da Baixada, a greve adquiriu caráter de símbolo maior da luta contra o autoritarismo vigente no período a partir da denúncia de sua manifestação particular no mundo do trabalho da região. Mais do que isso, a cobertura feita pelo jornal politizava a própria relação entre o grande capital, no caso específico o de origem internacional, e o aparelho de Estado sob controle militar.

O espaço fabril foi apresentado aos leitores como metáfora da própria sociedade brasileira sob o jugo ditatorial. Mais do que o próprio sindicato dos trabalhadores, foi o jornal que estendeu e aprofundou o significado da greve enquanto manifestação política. O Jornal da Baixada cria e pauta, literalmente, o vínculo entre o que acontece na fábrica e as demais frentes de luta política então emergentes na região e no país. Desde o início da cobertura do movimento grevista, a opção do jornal foi descrever os acontecimentos, adotando um ponto de vista narrativo que buscava colocar o leitor na posição de alguém que participava ativamente dos episódios. Esse intuito se materializava mediante dois expedientes. De um lado, os acontecimentos são apresentados dia a dia em tom vívido, quase folhetinesco; trabalhadores, sindicato e representantes patronais aparecem como personagens de um combate pontuado por golpes e contragolpes, ataque e defesa, e no qual os contendores começam se estudando, testam a força um do outro e finalmente

13 Jornal da Baixada. São João de Meriti, RJ: Editora Olho Vivo, maio/out. 1979, edição extra, p. 4. 
passam ao combate aberto; como em um filme, a ação se desenrola num crescendo, com direito a suspense e drama: os subtítulos presentes no texto da Edição Extra dedicada à cobertura da greve pontuavam esse crescendo: "A Virada - Quarta, 25"; "A Consolidação da Greve - Quinta, 26"; “Tudo Parado - Sexta, 27"; "Mulheres se Organizam - Sábado, 28”; "Lavradores Participam - Domingo, 29”; “A Greve Continua - Segunda, 30" ; “A Solidariedade - Terça, 31".

De outro lado, e também para escapar à repressão policial, os assuntos relativos às relações de trabalho na região da Baixada Fluminense eram abordados em uma seção especial da edição ordinária do Jornal "assinada" por Chico Bé, personagem fictício que também exprimia aquele tom jocoso, quase picaresco, que era marca da publicação aqui mencionada.

Chico Bé estava presente quando da eclosão da paralisação espontânea inicial que levou à parada total da fábrica e acompanhou in loco todo o desenrolar dos acontecimentos. Apresentando, assim, sua cobertura da greve (não importa se suas notícias eram ou não verificáveis para a argumentação ora exposta), o Jornal da Baixada buscava estabelecer uma identificação do conjunto dos trabalhadores da Baixada e alhures com o movimento reivindicativo dos operários da FIAT. Chico Bé dava voz ao trabalhador brasileiro explorado pelo patrão, e que devolvia na moeda da ironia e do sarcasmo o discurso edificante que, como regra, este utilizava para justificar a exploração.

O clima na FIAT Diesel estava carregado desde o ano anterior, quando um contingente de cerca de 1.800 empregados da empresa foi demitido. Além disso, a mencionada atitude da empresa de não abonar as faltas dos que não conseguiram chegar ao local de trabalho por ausência de condução quando da paralisação do transporte público na Baixada também contribuía para a insatisfação da força de trabalho.

Tal estado de ânimo coincidia com o início da mobilização sindical pela recomposição do valor de compra dos salários frente à inflação do período. Assembleia realizada no dia 22 de junho de 1979 deliberou a constituição de uma Comissão de Salário encarregada da elaboração de uma proposta de melhoria salarial a ser apresentada à direção fabril. Tal proposta, por sua vez, viria a ser aprovada em nova assembleia realizada uma semana depois, sendo encaminhada à FIAT no dia 4 de julho.

Após pedir um prazo de 16 dias para dar uma resposta à pauta de 33 itens apresentada pelos trabalhadores, a FIAT responde, afirmando sua intenção de discutir apenas dois itens daquela pauta. Ambos versando sobre a questão salarial exclusivamente, o que deixava claro a intenção da empresa de circunscrever as demandas da força de trabalho à questão econômica em sentido estrito sem, contudo, dar uma resposta concreta ao índice de reposição salarial que era pedido por aqueles trabalhadores. A empresa recorre a um exercício matemático confuso, segundo a definição dos representantes sindicais, visando justificar um pedido de adiamento da data-base do dissídio coletivo da sua força de trabalho, fazendo com que este coincidisse com o da categoria dos metalúrgicos do Rio de Janeiro como um todo. Como então afirmou ao Jornal da Baixada um dos componentes da Comissão Salarial: "a proposta dos patrões era enrolada de propósito [...]. Por isso eles só queriam discutir os outros pontos da minuta depois que a comissão respondesse à sua contraproposta". ${ }^{14}$

Na manhã do dia 23 de julho, uma segunda-feira, a Comissão de Salário encontrava-se reunida com a Delegação Sindical dos operários da FIAT a fim de avaliar a resposta dada pela direção fabril e encaminhar nova proposta à empresa,

14 Jornal da Baixada, edição extra, p. 2. 
quando chega a notícia de que o principal setor da fábrica acabara de cruzar os braços, exigindo que a política de demissões massivas que a FIAT vinha adotando fosse suspensa e que se fizesse o pagamento dos dias descontados aos que foram afetados pela greve rodoviária.

Os trabalhadores obtiveram, então, da empresa o compromisso de atendimento de ambas as reivindicações. O Diretor de Relações Industriais da FIAT, major Vitor Neto, garantiu que não haveria repressão ao movimento de paralisação caso não houvesse dano ao patrimônio da empresa, ressalvando, porém, que as horas paradas seriam descontadas. Medida de represália mais imediata foi a recusa do comparecimento à reunião com os representantes dos trabalhadores naquela tarde.

A reação da empresa, porém, não foi bem aceita pelos trabalhadores do galpão Brasília (maior e mais recente unidade da fábrica e onde se concentravam os trabalhadores mais novos e, também, mais radicalizados politicamente) e, na manhã do dia seguinte, 24 de julho, eles passaram a percorrer os demais setores da fábrica, conclamando os demais operários a aderir a uma total paralisação da produção. A fábrica parou integralmente. Ato contínuo, as instâncias de representação dos trabalhadores na FIAT e fora dela (Comissão de Salário, Delegação Sindical e Diretoria do Sindicato dos Metalúrgicos do Rio de Janeiro) convocaram uma assembleia geral dos trabalhadores da fábrica.

Na assembleia realizada no Clube Piauí, localizado ao lado da planta fabril, a proposta da FIAT de adiar a discussão da questão salarial foi unanimemente rejeitada. Por outro lado, a maioria dos presentes decidiu a favor da volta ao trabalho para aguardar a resposta da FIAT ao conjunto da pauta de reivindicações; sendo que esta agora passava a incorporar mais dois itens: fim da política de demissão em massa e pagamento dos dias descontados aos que ficaram sem condução para ir trabalhar.

Tal decisão não se deu de forma exatamente pacífica, pois a assembleia acabou terminando em uma briga mais ou menos generalizada promovida pelos líderes sindicais defensores da continuidade da greve (tendo à frente Luis Paulo Gianini, inspetor de qualidade e membro da Comissão de Salário) e cujo estopim ironicamente foi a intervenção de um metalúrgico aposentado condenando a paralisação ocorrida. Em referência específica ao episódio dessa primeira assembleia, José Ricardo Ramalho transcreve o depoimento de um dos líderes sindicais presentes:

Fomos para a assembleia. O Gianini já tinha dado um pau num engenheiro, um rapaz muito bom do ponto de vista da compreensão política e tudo o mais. Era da delegação, o Gianini invocou e botou o cara para fora no tapa. A ideia do Gianini era o poder no tapa. Aí fomos para a assembleia. Tinha a turma organizada dele. Assim como a gente tinha a de 64 , ele tinha a turma organizada dele. E a coisa que eu não queria fazer hoje... quando o negócio apertava, Pimentel (presidente do Sindicato dos Metalúrgicos) jogava para mim. [...] E eu enfrentei o troço, e consegui fazer, sem nenhuma vaidade, fazer com que a assembleia votasse a favor do retorno ao trabalho. Nós achávamos que aquela hora não era para fazer greve. Aí a turma do Gianini não se satisfez e saiu para a provocação, e foi aquilo que se deu, cadeirada para tudo quanto é lado, pau para lá e pau para cá. Eu fui parar na polícia. ${ }^{15}$

Na descrição do Jornal da Baixada, porém, as coisas se passaram de forma muito menos conflituosa:

15 RAMALHO, José Ricardo. Estado-patrão e luta operária: o caso FNM. Rio de Janeiro: Paz e Terra, 1989, p. 233-234. 
No final da Assembleia começou a discussão provocada por um metalúrgico aposentado. Nervoso, ele protestou contra a greve feita espontaneamente nos dois últimos dias. O ambiente esquentou. Cadeiras foram jogadas no palanque. A grande imprensa deu destaque, insinuando que houve briga entre os operários. Não é verdade. Os operários não brigaram entre si. Todos lamentaram a confusão que, felizmente, não abalou em nada a unidade dos trabalhadores. ${ }^{16}$

Pode-se ver aí que, ao minimizar a existência de divergências entre os trabaIhadores da FIAT, "novos" e "velhos"17, negando mesmo o que o próprio relato descreve, o jornal tanto deixava patente sua posição de apoio ao movimento quanto assumia um posicionamento político raro naquele momento histórico marcado pela radicalização do enfrentamento entre trabalhadores e empresariado: o de "pôr panos quentes" nas eventuais divergências internas ao movimento de mobilização dos trabalhadores em nome da causa maior que, de acordo com a posição do jornal, os unia. Tanto é assim que mesmo a atitude dos 200 trabalhadores do turno da noite de permanecerem parados, contrariando a decisão da assembleia e obviamente indicando a presença de divergências internas entre os operários, foi mencionada em tom conciliador ("sem que se registrassem maiores acidentes"). ${ }^{18}$

Quando chegam para trabalhar na manhã seguinte, os trabalhadores logo são inteirados por colegas que Luis Paulo Gianini, maior defensor da continuidade da greve na assembleia da noite anterior, havia sido demitido. Esse acontecimento marcou o início da greve e de sua narrativa em tom épico pelo Jornal da Baixada:

Quem já tinha trocado de roupa, ou ainda estava se preparando para começar o trabalho, voltou, para engrossar as fileiras da massa de operários que vinha, desde o fundo da fábrica, caminhando em direção ao portão, ao lado do Serviço de Pessoal. Todos os trabalhadores estavam presentes: exigiram que o Delegado Sindical, João Guerra, fosse tomar satisfações sobre o que estava acontecendo. A multidão gritava, exigindo a presença do operário que estava dentro do Serviço de Pessoal. ${ }^{19}$

Constituídos em assembleia ali mesmo e tendo a confirmação da demissão de Gianini, os operários decidiram entrar em greve e também destituir alguns dos componentes mais conciliadores da Comissão de Salário, substituindo-os por outros defensores da radicalização no enfrentamento com a empresa. A resposta da FIAT veio na forma de requisição de um contingente de policiais militares para ocupar as instalações da fábrica. De acordo com o jornal, o que se seguiu foi um embate entre a defesa dos trabalhadores do seu direito de permanência na fábrica que, por assim dizer, “também era deles", e o discurso patronal de defesa da prerrogativa de dispor de sua propriedade como melhor lhe aprouvesse:

Os trabalhadores, que discutiam pacificamente seus problemas, protestaram: "Não somos ladrões. Somos trabalhadores. Vão prender os ladrões. Nos deixem em paz", gritavam para os PMs que circulavam nas proximidades do portão, armados de metralhadoras, capacetes, escudos. [...]

O major Vítor Neto deu uma de dono da casa: "Vocês estão parados. Ou voltam ao trabalho ou saem da fábrica. Aqui é que não podem ficar”.

16 Jornal da Baixada, edição extra, p. 2.

17 Sobre o conflito de gerações presente na FIAT Diesel, tanto no cotidiano das relações de trabalho quanto no que diz respeito às relações sindicais, ver: RAMALHO, op. cit.

18 Jornal da Baixada, edição extra, p. 2.

19 Ibidem, p. 2. 


\begin{abstract}
$[\ldots]$
Os trabalhadores se retiram da fábrica e passam a aguardar o resultado da reunião que à tarde ocorreria na sede da Junta de Conciliação e Julgamento de Duque de Caxias. Nesta os representantes da FIAT se recusaram a aceitar a presença de Luis Paulo Gianini na mesa de negociação. Frente à pressão dos líderes sindicais presentes a presença daquele foi aceita, porém, não houve avanço concreto na reunião. A FIAT aparentemente resolvera adotar uma estratégia de ganhar tempo e esperar o movimento grevista perder forças. Esta postura foi acompanhada de um esforço de intimidação respaldado oficialmente pelo governo do general João Batista Figueiredo, o que deu ensejo a um irônico comentário do Jornal:

O dia amanheceu com a estrada que vai da Rio-Petrópolis até a fábrica lotada de policiais. Na fábrica, o policiamento era ainda mais forte. Lembrava campo de batalha. Seria essa a economia de guerra que o Figueiredo andou falando? ${ }^{20}$
\end{abstract}

O único fato novo do dia foi a criação de uma Comissão de Fábrica (encarregada da organização de piquetes, confecção de faixas, criação de um fundo de greve e divulgação do movimento), já que a reunião entre representantes dos trabalhadores, Ministério do Trabalho e negociadores da FIAT não havia apresentado nenhum resultado concreto. Nos termos do Jornal da Baixada, "os italianos nem respondiam. Talvez não soubessem falar português". ${ }^{21}$

Nesse ponto, o Jornal da Baixada assume não apenas o papel de narrador dos acontecimentos do ponto de vista dos grevistas, ou, melhor dizendo, de propositor de uma interpretação da greve que a tomava como exemplo de heroísmo e solidariedade dos trabalhadores na luta pela melhoria das condições de vida de suas famílias e, no limite, de toda a população da Baixada Fluminense (nesse sentido, a presença da FIAT aparece quase como uma metáfora do processo histórico de construção da Baixada Fluminense como lugar marcado pela exploração de seus recursos econômicos e humanos), mas passa também a apontar as lacunas e intencionalidades do discurso da empresa no seu embate com a sua força de trabalho. Dessa forma, o jornal se torna ele mesmo uma parte do movimento grevista. Ao narrá-lo, ele registra a memória da greve e se propõe ao papel de educador político dos que dela participam, fazendo desses atores exemplo para futuros movimentos e mobilizações de trabalhadores que possam ocorrer.

Por outro lado, ao narrar o comportamento do lado patronal - dos negociadores da FIAT, o Jornal da Baixada desnuda a estratégia da empresa de não permitir o transbordamento da demanda salarial para outros aspectos da política de gestão da força de trabalho por ela adotada:

O comportamento dos diretores da Fiat pode ser bem compreendido por dois exemplos. Primeiro, a resposta ao pedido de que os trabalhadores das empreiteiras tivessem os mesmos direitos que os trabalhadores da própria Fiat. A Fiat respondeu que não tinha nada a ver com isso. Perguntou se os metalúrgicos eram agora advogados da construção civil. A argumentação dos trabalhadores foi clara. As empreiteiras não são mais do que uma forma da Fiat se livrar de encargos sociais de seus empregados e, principalmente, do pagamento da taxa de insalubridade. E acordos do mesmo tipo já tinham sido feitos antes, como era o caso da Verolme..$^{22}$

\footnotetext{
20 Jornal da Baixada, edição extra, p. 2.

21 Ibidem, p. 3.

22 Ibidem, p. 3.
} 
Frente à intransigência da empresa na mesa de negociação, a mobilização dos trabalhadores se amplia, passando a incorporar também as mulheres (com a redação de uma "Carta às Esposas") e a buscar obter o apoio da população do município à greve (com a organização de ato público na Praça do Pacificador, no centro de Duque de Caxias).

Os grevistas buscaram o apoio do Sindicato dos Metalúrgicos de Volta Redonda, bem como iniciaram uma campanha de arrecadação de fundos. Em contrapartida, demonstraram solidariedade à luta pela terra encabeçada pelos posseiros em Xerém (distrito de Duque de Caxias onde está a fábrica da FIAT) e divulgaram o pedido de apoio feito pelos posseiros ao movimento grevista. Enfim, a greve foi marcada por um forte espírito de politização e apresentada nas páginas do Jornal da Baixada como um evento de alcance muito mais amplo que a pura e simples luta por melhores salários dos empregados de uma empresa.

A greve foi transfigurada numa luta contra toda forma de autoritarismo e este se tornou sinônimo de barbárie. Pois que, em contraposição à imagem de desordem impingida usualmente pelos veículos de comunicação de propriedade de grandes grupos empresariais aos movimentos de mobilização política dos trabalhadores, o Jornal da Baixada procurou reforçar o sentido de manifestação civilizada e cidadã apresentado pela greve:

Na manhã de terça-feira, quem passou pela rodovia Washington Luís enfrentou um denso nevoeiro que só clareava no sopé da serra, na entrada para a FIAT. Às 7 horas, os grevistas estavam lá, em bloco, formando um piquete de cerca de mil homens. Estavam tranquilos, na única entrada que dá acesso à fábrica.

Às 7 e meia, os operários se deslocaram para o Clube Piauí. Mais uma assembleia. Os policiais pareciam ter desistido de assistir a tal demonstração de ordem e unidade. As ruas estavam limpas. [...] Na assembleia, foi lido o noticiário do movimento dos operários da construção civil em Belo Horizonte e da morte de Oracílio Martins Gonçalves. A assembleia fez um minuto de silêncio.

O movimento grevista, portanto, aparecia como parte de uma luta de alcance nacional por melhores condições de trabalho e vida. Luta esta que sofria o constante ataque das forças da repressão. Tratava-se assim tanto de um enfrentamento do "patrão privado" quanto da "autoridade pública”, então irmãos siameses. Tratava-se também da afirmação da identidade e da dignidade de classe dos operários frente ao poder da empresa e do Estado ditatorial. O Jornal da Baixada reverbera em alto e bom som nas suas páginas a palavra de ordem da resistência e da solidariedade que soou na assembleia desse dia, 31 de julho, em que sua Edição Extra veio a público:

A assembleia decidiu: "Não vai ser um mês a mais de feijão com farinha que vai fazer o operariado arredar o pé de seus direitos. Não é por medo de passar fome que a greve vai ser suspensa. Contamos com a colaboração do povo. Além disso, já estamos acostumados a passar fome praticamente o ano inteiro. Essa fome vem desde que os portugueses botaram o pé nessa terra". ${ }^{23}$

Estas qualidades do movimento grevista (politização, solidariedade com outros segmentos da população, democracia) são vistas pelo jornal como exemplo para outros movimentos. Reforçando essa ideia, na edição do periódico, o já mencionado presidente do Sindicato dos Metalúrgicos do Rio de Janeiro, Oswaldo

23 Jornal da Baixada, edição extra, p. 3. 
Pimentel, aponta a greve da FIAT Diesel como um possível marco inicial do movimento grevista que virá efetivamente ocorrer no estado alguns meses depois:

A greve da FIAT está cem por cento ótima. Ela está demonstrando que a opressão de 15 anos de arbítrio criaram condições impossíveis de suportar. [...] Esse movimento na FIAT tem sido de enorme importância. Representa um fortalecimento para o movimento que vai se iniciar na área do Rio de Janeiro. A categoria já se encontra bastante mobilizada e disposta de fato a atingir seus objetivos. ${ }^{24}$

A greve de julho de 1979 na FIAT Diesel assumiu para o Jornal da Baixada, portanto, um caráter exemplar em termos de mobilização política bem-sucedida. A própria repercussão do movimento por meio das páginas desse periódico significou a disseminação de uma conscientização de seus leitores para o fato de que a greve era essencialmente uma das faces de um movimento político maior. Por outro lado, o acordo finalmente obtido com a empresa foi também utilizado pelo jornal como alerta para futuros movimentos de luta dos trabalhadores por melhores condições salariais e de trabalho:

A Fiat só aceitou a volta de Luis Paulo Gianini se ele assinasse uma carta prometendo comportar-se de acordo com as normas disciplinares da empresa. E assim a greve acabou. A Fiat terminou capitulando. A cartinha, um detalhe ridículo, acaba escondendo uma coisa muito séria: as arbitrariedades e péssimas condições de trabalho que acenderam o estopim da greve. [...]

Dia 6, segunda-feira, recomeçou o trabalho. No mesmo dia, a assembleia concluiu que a vitória foi basicamente política, já que o aumento representou pouco. A unidade do movimento levantou o ânimo dos trabalhadores e assustou a direção da Fiat. Agora, é abrir os olhos. A direção da empresa só pensa em dividir a classe. Questão de tempo..25

Embora o tom presente na avaliação exposta acima indicasse a vitória dos trabalhadores, a palavra de ordem divulgada nas páginas do jornal pouco tempo após o fim da greve passou a ser "não confiar em promessa de patrão", já que os trabaIhadores da FIAT, ao aceitar o acordo proposto pelo juiz do Tribunal Regional do Trabalho no dia $1^{\circ}$ de julho, prevendo um aumento de $26 \%$ para os trabalhadores em seu conjunto, com o acréscimo do índice de reposição estabelecido pelo Governo Federal para os que auferiam os menores salários, teriam deixado de insistir na crítica às formas de gestão do trabalho vigentes naquela empresa. Nas palavras de Chico Bé:

Como era de se esperar, a equiparação salarial da Fiat, discutida e acertada entre funcionários e patrões na greve de julho de 79, saiu segundo os critérios patronais. Representantes da delegação sindical afirmam que, na verdade, o que saiu foi apenas uma espécie de arredondamento, mal intencionado e desonesto. Prevalecendo os critérios calhordas, [...], foi feita a avaliação pelos chefetes em cima dos quatro itens básicos: Quantidade, Qualidade, Colaboração ou puxa-saquismo e Disciplina ou galho-dentro. É óbvio e descarado, que nenhuma avaliação feita por chefes, com o objetivo de correção salarial, vai medir sinceramente a capacidade de um trabalhador. Acabou acontecendo o que todo mundo esperava: o ponto básico da análise foi a tal de "colaboração", beneficiando, com isso, os afilhados dos puxa-sacos. Ficou uma lição

24 Ibidem, p. 4.

25 Jornal da Baixada, n. 3, p. 2. 
da maior importância. Não há como confiar em patrão. Não há como negociar prazo em cima de reivindicação contra essa gente. Ou resolve os problemas no clima de greve, ou dança. Adiou, voltou a trabalhar confiando em promessa, cachimbo caiu, trabalhador levou ferro. ${ }^{26}$

O jornal reafirmava, assim, seu caráter de instrumento de formação política e de órgão de apoio a todo e qualquer movimento organizado de mobilização popular. Assumindo posição explícita de defesa da greve, da unidade dos trabalhadores e da solidariedade entre estes e o conjunto da população da Baixada Fluminense, o Jornal da Baixada se expunha como um órgão classista (sem ser sindical) e de oposição ao autoritarismo do governo (responsável pelas leis e políticas arbitrárias e pela repressão sobre os movimentos sindical e popular) e do patronato (autoritário nas relações de trabalho imediatas).

Sendo publicado em uma região marcadamente violenta, carente de serviços básicos e com uma tradição de política autoritária e fisiológica, o Jornal da Baixada também assumiu postura oposicionista em relação às correntes que controlavam o governo estadual e dos municípios da Baixada.

Para este texto, não faz muita diferença se sua avaliação da greve dos operários da FIAT Diesel era equilibrada ou não. Importa considerar que o jornal soube identificar o que o movimento grevista trazia de novo em termos de sua espontaneidade e dos temas objeto de reivindicação, e se propôs a assumir a tarefa pedagógica de disseminação de uma imagem da organização dos trabalhadores como algo positivo e indispensável à afirmação da cidadania.

\section{"Pobre, atrevido, independente": o Jornal da Baixada como parte do fazer-se dos trabalhadores de uma região periférica}

O texto aqui apresentado constitui uma incursão a uma fonte muito rica de registro da luta operária no Brasil, num momento de sua história recente, em que reivindicações econômicas e políticas se conjugavam de forma muito intensa. Naquele curto período, muito tenso e denso para fins de análise, se revelam em cores vivas e sons claros as imagens e as vozes dos protagonistas, por meio de um veículo que se identifica plenamente com suas ações e objetivos.

A relevância do objeto estudado se encontra no registro do movimento operário brasileiro "para além do $A B C$ ". As greves e os movimentos de metalúrgicos paulistas, tendo sua importância histórica reconhecida, contam com uma análise historiográfica já bastante rica, além de possuírem, inclusive, um rico registro por parte dos meios de comunicação escritos e até mesmo audiovisuais. De outro lado, vemos como ainda vigorosa uma interpretação da retomada da força do movimento sindical, a categoria dos metalúrgicos à frente, que minimiza ou mesmo desconsidera a presença dessa retomada no estado do Rio de Janeiro - no caso abordado neste texto, numa região periférica à capital estadual, e tradicionalmente vista como área-dormitório. ${ }^{27}$

26 Jornal da Baixada, n. 6, p. 8.

27 Por exemplo, SANDOVAL, Salvador. Os Trabalhadores param: greves e mudança social no Brasil (19451990). São Paulo: Ática, 1994. Este autor chega a afirmar que o Rio de Janeiro "continuou a ser um centro inexpressivo de atividades grevistas, possivelmente devido à menor militância das associações coletivas nas áreas mais industrializadas" (SANDOVAL, op. cit., p. 136). Isso dito a propósito do ano de 1979, no qual eclodiu no estado uma greve que chegou a contar com a adesão de 250.000 metalúrgicos! 
Estender esse registro e essa análise a outras regiões brasileiras, onde o movimento operário é portador de reivindicações, de formas organizativas e tradições próprias, embora vivendo problemas e conjunturas comuns ao conjunto da classe trabalhadora brasileira, só tende a enriquecer a memória do movimento operário e popular em nossa sociedade.

Dessa forma, se a constituição de uma identidade de classe se faz no seio do próprio processo de luta tanto por direitos quanto por melhores condições de existência, no espaço do trabalho e fora dele, o Jornal da Baixada buscou ocupar um lugar no desenrolar desse processo ao longo de um curto, porém importantíssimo, momento histórico: o ano chave de 1979.

Procurou-se mostrar aqui a presença neste contexto histórico de formas de mobilização originais, as quais tinham como marca a busca pela unificação de reivindicações aparentemente díspares - metalúrgicos exigindo melhores condições salariais e de trabalho, trabalhadores rurais lutando pela posse da terra em que sempre viveram, mães e pais de alunos exigindo acesso a uma educação de qualidade e a um digno atendimento nos serviços públicos de saúde, etc. - mas que puderam ser percebidas pelos seus próprios protagonistas como parte de uma mesma luta mais geral pela melhoria das condições de vida de uma região que havia se constituído historicamente como propiciadora de lucro apenas para os proprietários dos meios de produção.

Nesse esforço, o Jornal da Baixada, em sua curta existência, atuou como um verdadeiro "partido político", na medida em que, muito mais do que um divulgador dos acontecimentos políticos relevantes na região da Baixada Fluminense, pautou-se pela necessidade de uma soma de forças da população da região no enfrentamento das formas por intermédio das quais ali se manifestava o conjunto de relações econômicas e políticas garantidoras da condição de subalternidade da classe operária frente ao capital e ao Estado. Menos que um órgão de classe, o Jornal da Baixada foi o órgão de um fazer-se de classe permanentemente em movimento.

Recebido em 21/03/2013 Aprovado em 08/06/2013 